\title{
Risk Factors for Decreased Pelvic Floor Muscle Strength: Which is More Effective?
}

\author{
Omer DEMIR ${ }^{1}$, Cihan COMBA²
}

Erzurum, Turkey

\begin{abstract}
OBJECTIVE: The aim of this study was to assess whether cigarette smoking weakens the pelvic floor and to determine its effective impact relative to other factors.

STUDY DESIGN: Between September 2017 and September 2018, 250 patients admitted to an outpatient gynecology clinic was examined by a single physician and their anamnesis were taken, the data obtained were evaluated retrospectively. As a result of the examination, the pelvic floor muscle strength was evaluated according to the Modified Oxford Scale and the patients evaluated as 1/5 and 2/5 were grouped as having weak muscle strength and the rest were grouped as having high muscle strength. The intention was then to compare these two groups. The SPSS 21.0 for Windows program was used to perform statistical evaluations. Comparative analysis was performed with regression analysis.
\end{abstract}

RESULTS: 250 women participated in the study. 4 patients had muscle strength of $1 / 5$; while 40 patients had muscle strength of $2 / 5(17.6 \%)$. Patients with muscle strength of $1 / 5$ and $2 / 5$ were grouped as weak muscle strength. Advanced age, increased parity, smoking, and obesity are risk factors for a decrease in pelvic floor muscle strength $(p<0.05)$. Binary logistic regression analysis was performed to determine which of these factors has the greatest impact on pelvic floor muscle strength. Smoking has a 7-fold effect on decreased muscle strength (OR: 7.925) and obesity has a 5-fold impact (OR: 5.374).

CONCLUSION: Although the mechanism of the effect of cigarette smoking on the pelvic floor is not known, it should be remembered that this effect has an adverse impact together with other factors which also have proven detrimental effects.

Keywords: Cigarette smoking, Muscle strength, Pelvic floor

Gynecol Obstet Reprod Med 2021;27(1):56-59

\section{Introduction}

The anatomical support of the pelvic floor is ensured by the cooperation of the muscles and the connective tissue around it (1). The main structure of this support is the levator ani muscle complex. The weakening of this structure, which

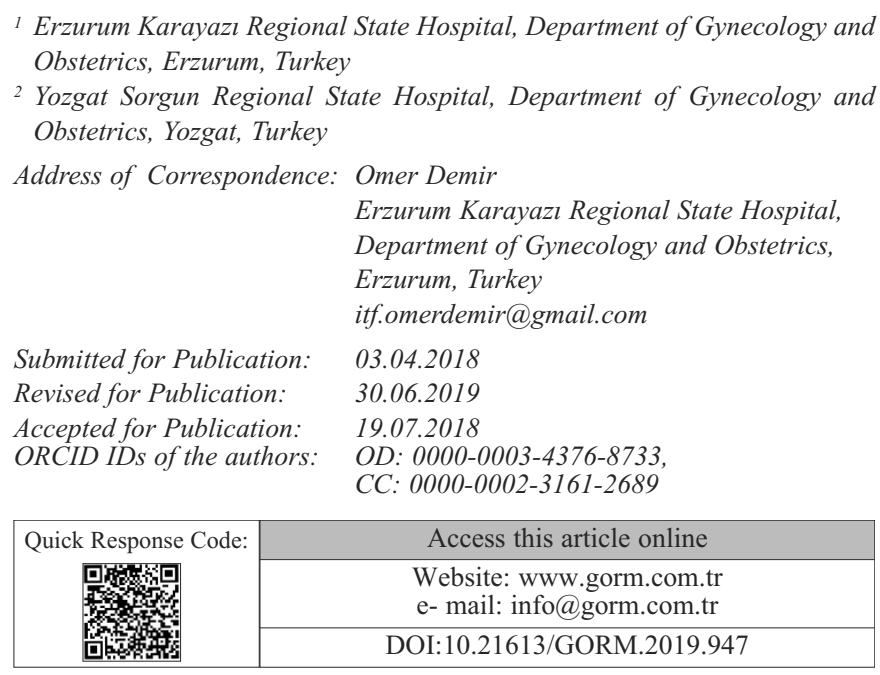

How to cite this article: Demir O. and Comba C. Risk Factors for Decreased Pelvic Floor Muscle Strength: Which is More Effective? Gynecol Obstet Reprod Med 2021;27(1):56-59 constitutes the most significant support, forms the basis of pelvic floor disorders (1).

The concept of disorders of the pelvic floor covers a wide range of clinical conditions. These are urinary and fecal incontinence, pelvic organ prolapse and defecation dysfunction (2). These are symptomatic disorders that are reflected in the clinic, and it has been observed that the pelvic floor tends to weaken and become unable to perform its task before reaching this stage.

Several methods have been described to assess pelvic floor muscle strength. The pelvic floor is checked to determine muscle tissue integrity, symmetry, and power. Palpation through the vagina or rectum assists in assessing the pelvic floor squeezing strength and levator muscle thickness. The tone and power of the pelvic floor muscles can be evaluated by asking the patient to contract the pelvic floor muscles around the examining fingers (3). An instrument muscle test is also available, but other techniques have not demonstrated adequate clinical application in the evaluation of POP (3). Electromyography with needle electrodes allows the visualization of the individual motor unit action potentials but has not extended beyond experimental use (3). Other less common 
methods include; urethral, vaginal and anal pressure recording or pudendal nerve terminal motor latency test. Their value is controversial and rarely clinically indicated (3).

Several factors have been shown to cause weakening of the pelvic floor and studies have been carried out and continue to be undertaken. The factors which have been emphasized most causally are; parity, type of delivery, increased age, menopause, hysterectomy, etc. $(4,5)$.

When the symptoms of these disorders are reflected in the clinic, smoking is shown to be risk factors, but no studies have been identified in the literature relevant to the effect of smoking on the weakening of the pelvic floor.

For this reason, this study has been undertaken to see whether cigarette smoking weakens the pelvic floor and to determine its effective impact relative to other factors.

\section{Material and Method}

Patients who were admitted to the Gynecology and Obstetrics outpatient clinic of a regional state hospital between September 2017 and September 2018 were evaluated. The study was carried out retrospectively using the patients' routine vaginal examination notes. For the purpose of the study, the inclusion and the exclusion criteria were determined. The patients included in the study had not had any other conditions, previous pelvic surgery or any history of drug use that may have affected their pelvic floor muscle strength. Patients who showed clinically significant pelvic organ prolapse during vaginal examination and who had symptomatic urinary incontinence were not included in the study. Furthermore, patients should not be virgins as the muscle strength of the patients needed to be evaluated.

Vaginal examinations were performed, and pelvic floor muscle strength was evaluated before taking the anamnesis of the patients. Then, the patients' history was obtained. Questions were asked about smoking, parity, type of birth, height and weight, and Body Mass Index (BMI) was calculated. In this manner, the physician was not affected by the patients' history. The evaluation of pelvic floor muscle strength was measured manually as a subjective method in our study and therefore this method was intended to avoid any negative influences.

During a routine vaginal examination, the patients were informed as to how to perform an examination to test pelvic floor muscle strength and how to obtain the measurements and measurements were delivered accordingly.

The Modified Oxford Grading System is used to evaluate the strength of the pelvic floor muscles by using vaginal palpation. Laycock developed this method (6). It consists of a six-point scale: $0=$ no contraction, $1=$ flicker, $2=$ weak, 3 $=$ moderate, $4=\operatorname{good}$ (with lift) and $5=$ strong. All assessments were carried out by the same clinician. It is an easy method to use and does not require additional equipment (7). Inter-rater reliability for vaginal palpation was found to be high in the study by Ferreira et al. in $2011(\kappa=0.33,95 \%$ confidence interval 0.09 to 0.57$)(8)$.

Patients with muscle strength of $1 / 5$ and $2 / 5$ were grouped as weak muscle strength. The other patients were determined as high muscle strength to form a comparative group.

In our study, ethics committee approval was not required as routine gynecological examination information of patients was used. Authorization was obtained from the hospital for the data could be used (20.11.2018).

Informed consent was obtained from patients to use the examination and anamnesis information. The study was created based on the principles set out in the Declaration of Helsinki.

\section{Statistical Analysis}

The SPSS 20 program designed for Windows was used for statistical analysis. All continuous variables were defined as mean and standard deviations. Categorical variables were shown as a percentage of the total group. A p-value $<0.05$ was determined as statistically significant, and all statistical tests were two-sided.

Pearson's chi-square independence test was used to examine the interdependence of the categorical data.

The statistical significance of the effects of independent variables on pelvic floor muscle strength was the primary goal of the study. A binary logistic regression analysis was performed to predict the impact of independent variables.

\section{Results}

Two hundred and fifty women participated in the study. The average age of the women participating in the study was $32.46 \pm 10.38$; parity average was $3.29 \pm 2.54$; 63 (25.2\%) were active smokers. Of the patients, $129(51.6 \%)$ had a normal BMI score, and 26 (10.4\%) were obese. Four patients had muscle strength of $1 / 5$ and 40 patients had muscle strength of $2 / 5$ (17.6\%). Patients with muscle strength of $1 / 5$ and $2 / 5$ were grouped as weak muscle strength. The other patients were determined as high muscle strength as a comparative group. Factors believed to affect pelvic floor muscle strength were calculated and compared between the two groups (Table I). As shown in the table, advanced age, increased parity, smoking, and obesity are risk factors for decreased pelvic floor muscle strength.

Binary logistic regression analysis was performed to determine which of these factors had a greater impact on pelvic floor muscle strength than others. Table II shows this regression analysis. According to this analysis, it can be seen that smoking and obesity have significantly more impact than other factors. It has been observed that smoking has a 7-fold effect on decreased muscle strength and obesity has a 5-fold impact. 
Table I: Analysis of factors that are thought to have an effect on pelvic floor muscle strength

\begin{tabular}{|c|c|c|c|}
\hline & $\begin{array}{l}\text { Pelvic floor muscle strength } \\
(1 / 5+2 / 5) n=44\end{array}$ & $\begin{array}{l}\text { Pelvic floor muscle strength } \\
(3 / 5+4 / 5+5 / 5) \quad n=206\end{array}$ & $p$ \\
\hline Age & $44.7 \pm 10.1(25-74)$ & $29.8 \pm 8.35(18-48)$ & $p=0.00(p<0.01)^{*}$ \\
\hline Parity & $6.2 \pm 2.4(1-12)$ & $2.6 \pm 2.1(0-8)$ & $p=0.00(p<0.01)^{*}$ \\
\hline Smoking & $23 / 44(52.3 \%)$ & $40 / 206(19.4 \%)$ & $p=0.00(p<0.01)^{*}$ \\
\hline Type of birth & $\begin{array}{l}\text { Normal vaginal delivery- } 37 / 44(84.1 \%) \\
\text { Cesarean section- } 1 / 44(2.3 \%) \\
\text { NVD+CS- } 6 / 44(13.6 \%)\end{array}$ & $\begin{array}{l}\text { Normal vaginal delivery- } 138 / 206(84.7 \%) \\
\text { Cesarean section- } 14 / 206(8.6 \%) \\
\text { NVD + CS- } 11 / 206(6.7 \%)\end{array}$ & $p=0.142^{*}$ \\
\hline Body Mass Index & $29.1 \pm 3.85(21.5-37.1)$ & $22.8 \pm 3.7(15.4-34.2)$ & $p=0.00(p<0.01)^{*}$ \\
\hline BMI Status & $\begin{array}{l}\text { Underweight- } 1 / 44(2.3 \%) \\
\text { Normal weight- } 7 / 44(15.9 \%) \\
\text { Overweight- } 18 / 44(40.9 \%) \\
\text { Obesity- } 18 / 44(40.9 \%)\end{array}$ & $\begin{array}{l}\text { Underweight- } 31 / 206(15 \%) \\
\text { Normal weight- } 122 / 206(59.2 \%) \\
\text { Overweight- } 45 / 206(21.8 \%) \\
\text { Obesity- } 8 / 206(3.9 \%)\end{array}$ & $p=0.00(p<0.01)^{*}$ \\
\hline
\end{tabular}

*Pearson chi-square test

Table II: Comparison of the effects of factors affecting pelvic floor muscle strength

\begin{tabular}{lrrrrrr}
\hline & B & SE & Wald & Df & $p$ & OR \\
\hline Age & -3.166 & 1.110 & 8.138 & 1 & 0.004 & 0.042 \\
Parity & -1.456 & 0.376 & 15.030 & 1 & 0.000 & 0.233 \\
Type of Birth & -0.354 & 0.346 & 1.046 & 1 & 0.306 & 0.702 \\
Smoking & 2.070 & 0.518 & 15.975 & 1 & 0.000 & 7.925 \\
Body Mass Index Status & 1.682 & 0.589 & 8.144 & 1 & 0.004 & 5.374 \\
\hline
\end{tabular}

B: Coefficient of regression, SE: Standard error, df: Coefficient of freedom, OR: Odds ratio

\section{Discussion}

Having regard to studies undertaken to date; parity comes in as the first of the factors that cause weakening of the muscle strength of the pelvic floor. In 2003, Delancey, et al. showed that damage to the levator ani muscle and local nerves during each birth leads to a weakening of pelvic floor muscle strength (9). This conclusion was also supported in 2006 by the work of Chen, et al (10).

Increased age has also been shown as a further factor negatively affecting the pelvic floor. In a study of 2070 women, an increased incidence of pelvic floor disorders was shown to manifest with increasing age (11).

In a meta-analysis of 22 studies conducted to predict the risk of obesity on pelvic organ prolapse, overweight and obese women have been shown to have a $40-50 \%$ greater risk of prolapse compared to women of normal weight (risk ratio 1.36, 95\% CI $1.20-1.53$ and $1.47,95 \%$ CI $1.35-1.59$, respectively) (12). The effect of these three factors, which have been shown to be the most important risk factors seen in the studies, was also noted in our study. In the current study, increased age, obesity and increased parity have been shown to significantly weaken the pelvic floor $(p<0.001)$.
One of the issues that have proven to be controversial for many years has been the effect of the delivery method on the pelvic floor. For many years, studies have been published indicating that normal vaginal delivery does not weaken the pelvic floor if evaluated independently of parity $(13,14)$. However, in a recently published meta-analysis, in which 9 studies and 4491 patients were involved, cesarean section was proposed to protect the pelvic floor, and statistically, significant improvement was observed in the cesarean group in all components of pelvic floor disorders (15). In the current study, it was observed that the type of delivery did not weaken the pelvic floor. Statistically, no difference was found between the types $(p=0.142)$.

A study that directly examines the effect of smoking on the pelvic floor has not been found in the literature. It is asserted that smoking may lead to pelvic floor disorder, but it does not show its mechanism or the extent of its impact. In our study, smoking was found to decrease pelvic floor strength more than the other factors. In the regression analysis, the effect of smoking was significantly higher than all other factors (Table II).

It is uncertain on what basis and to which mechanism it is possible to attribute this to smoking, however, the predicted mechanism is that it breaks down the collagen metabolism and 
consequently decreases the strength and weakens the muscle strength of the pelvic floor.

Our study is the first study of its kind to examine the effect of smoking on the pelvic floor. The weakness of the study is the manual evaluation of pelvic floor muscle strength.

However, by way of standardization, all examinations were performed by the same physician, and thus different evaluations between clinicians were avoided. In addition, the demographic characteristics of the patients were also obtained by the physician after the examination. Furthermore, this manual evaluation is a method that has been applied and accepted in the scientific world for many years.

\section{Conclusion}

Although the mechanism of the effect of cigarette smoking on the pelvic floor is not known, it should be remembered that this effect has an adverse impact together with other factors which also have proven negative effects.

Every patient seen in the clinic should be questioned in this respect and informed about the negative effects.

\section{Acknowledgment: None}

Funding statement: No funding was received for this study. Conflicts of Interest: The authors declare that they have no conflicts of interest.

Authors Contributions: OD: Project development, data collection, analysis, interpretation of data, manuscript writing CC: Analysis, interpretation of data, manuscript writing, revising the manuscript.

\section{References}

1. Stepp KJ. Walters MD. Anatomy of the lower urinary tract, rectum and pelvic floor. In: Walters M. Karram M. editors. Urogynecology and Reconstructive Surgery, 3, Philadelphia: Mosby; 2007. p.24.

2. Mannella P. Palla G. Bellini M. Simoncini T. The female pelvic floor through midlife and aging. Maturitas. 2013;76(3):230-4. doi: 10.1016/j.maturitas.2013.08.008.

3. Bo K. Frawley HC. Haylen BT. Abramov Y. Almeida FG. Berghmans B. et al. An International Urogynecological Association (IUGA)/International Continence Society (ICS) joint report on the terminology for the conservative and nonpharmacological management of female pelvic floor dysfunction. Int Urogynecol J. 2017;28(2):191-213. doi: 10.1007/s00192-016-3123-4.

4. Jelovsek JE. Maher C. Barber MD. Pelvic organ prolapse. Lancet. 2007;369(9566):1027-38. doi: 10.1016/S0140-

\section{6(07)60462-0.}

5. Vergeldt TF. Weemhoff M. IntHout J. Kluivers KB. Risk factors for pelvic organ prolapse and its recurrence: a systematic review. Int Urogynecol J. 2015;26(11):1559-73. doi: $10.1007 / \mathrm{s} 00192-015-2695-8$.

6. Laycock J. Clinical evaluation of the pelvic floor. In: Schussler B. Laycock J. Norton P. Stanton SL. editors. Pelvic Floor Re-education. London, United Kingdom: Springer-Verlag; 1994. p. 42-8.

7. Bo K. Sherburn M. Evaluation of female pelvic-floor muscle function and strength. Phys Ther. 2015;85(3):269-82.

8. Ferreira CH. Barbosa PB. de Oliveira Souza F. Antonio FI. Franco MM. Bo K. Inter-rater reliability study of the modified Oxford grading scale and the Peritron manometer. Physiotherapy. 2011;97(2):132-8. doi:10.1016/ j.physio.2010.06.007.

9. DeLancey JO. Kearney R. Chou Q. Speights S. Binno S. The appearance of levator ani muscle abnormalities in magnetic resonance images after vaginal delivery. Obstet Gynecol. 2003;101(1):46-53. doi:10.1016/s0029-7844 (02)02465-1.

10. Chen L. Ashton-Miller JA. Hsu Y. DeLancey JO. Interaction among apical support, levator ani impairment, and anterior vaginal wall prolapse. Obstet Gynecol. 2006;108(2):324-32. doi:10.1097/01.AOG. 0000227786. 69257.a8.

11. Luber KM. Boero S. Choe JY. The demographics of pelvic floor disorders: current observations and future projections. Am J Obstet Gynecol. 2001;184(7):1496-501. doi: $10.1067 / \mathrm{mob} .2001 .114868$.

12. Giri A. Hartmann KE. Hellwege JN. Velez Edwards DR. Edwards TL. Obesity and pelvic organ prolapse: a systematic review and meta-analysis of observational studies. Am J Obstet Gynecol. 2017;217(1):11-26. doi: 10.1016/ j.ajog.2017.01.039.

13. Afshari P. Dabagh F. Iravani M. Abedi P. Comparison of pelvic floor muscle strength in nulliparous women and those with normal vaginal delivery and cesarean section. Int Urogynecol J. 2017;28(8):1171-5. doi: 10.1007/s00192-016-3239-6.

14. Mendes Ede P. Oliveira SM. Caroci Ade S. Francisco AA, Oliveira SG, Silva RL. et al. Pelvic floor muscle strength in primiparous women according to the delivery type: cross-sectional study. Rev Lat Am Enfermagem. 2016; 24:e2758.doi: 10.1590/1518-8345.0926.2758.

15. Yang XJ. Sun Y. Comparison of caesarean section and vaginal delivery for pelvic floor function of parturients: a meta-analysis. Eur J Obstet Gynecol Reprod Biol. 2019;235:42-8. doi: 10.1016/j.ejogrb.2019.02.003. 